\title{
Synthesis of Silver Nanoparticles from the Aqueous Extract of Leaves of Ocimum sanctum for Enhanced Antibacterial Activity
}

\author{
Charusheela Ramteke, Tapan Chakrabarti, Bijaya Ketan Sarangi, and Ram-Avatar Pandey \\ Environmental Biotechnology Division, National Environmental Engineering Research Institute, Nagpur 440 020, India \\ Correspondence should be addressed to Ram-Avatar Pandey; ra_pandey@neeri.res.in
}

Received 9 February 2012; Revised 19 July 2012; Accepted 19 July 2012

Academic Editor: Alberto Ritieni

Copyright (C) 2013 Charusheela Ramteke et al. This is an open access article distributed under the Creative Commons Attribution License, which permits unrestricted use, distribution, and reproduction in any medium, provided the original work is properly cited.

\begin{abstract}
The field of nanotechnology is the most active area of research in modern materials science. Though there are many chemical as well as physical methods, green synthesis of nanomaterials is the most emerging method of synthesis. We report the synthesis of antibacterial silver nanoparticles (AgNPs) using leaf broth of medicinal herb, Ocimum sanctum (Tulsi). The synthesized AgNPs have been characterized by UV-Vis spectroscopy, transmission electron microscopy (TEM), and X-ray diffractometry. The mean particle of synthesized NPs was found to be $18 \mathrm{~nm}$, as confirmed by TEM. The qualitative assessment of reducing potential of leaf extract has also been carried out which indicated presence of significant amount of reducing entities. FTIR analysis revealed that the AgNPs were stabilized by eugenols, terpenes, and other aromatic compounds present in the extract. Such AgNPs stabilized by Tulsi leaf extract were found to have enhanced antimicrobial activity against well-known pathogenic strains, namely Staphylococcus aureus and E. coli.
\end{abstract}

\section{Introduction}

In recent years, researchers in the field of nanotechnology are finding that metal nanoparticles have all kinds of previously unexpected benefits. They are mostly prepared from noble metals, that is, silver, gold, platinum and palladium, silver nanoparticles (AgNPs) being most exploited [1]. They find applications in various fields like medicine, electronics, energy saving, environment, textile, cosmetics, and so forth. Owing to their applicability in such wide sectors, their demand is increasing at an overwhelming rate. The increased demand has consequently resulted in increased production. Researchers are continuously developing newer methods for synthesis of highly monodisperse AgNPs which are efficient in terms of synthesis rate as well as energy usage.

Conventionally, nanomaterials are synthesized using either chemical or physical methods which include sol process, micelle, chemical precipitation, hydrothermal method, pyrolysis, and chemical vapour deposition [2]. Some of these methods are easy and provide control over crystallite size by restoring the reaction environment. But problem still exists with the general stability of the product and in achieving monodisperse nanosize using these methods [3]. Moreover, many of the conventional techniques have been found to be capital intensive and inefficient in materials and energy use [4].

Biological methods have emerged as an alternative to the conventional methods for synthesis of NPs. Synthesis of inorganic nanoparticles by biological systems makes nanoparticles more biocompatible and environmentally benign [5]. Moreover, the process is cost effective too [1]. Many bacterial as well as fungal species have been used for silver nanoparticles synthesis [6]. But most of them have been reported to accumulate AgNPs intracellularly. Intracellular synthesis always takes longer reaction times and also demands subsequent extraction and recovery steps. On the contrary, plant extract mediated synthesis always takes place extracellularly, and the reaction times have also been reported to be very short compared to that of microbial synthesis. Most importantly, the process can be suitably scaled up for large scale synthesis of NPs [7].

Many plants such as Pelargonium graveolens [8], Medicago sativa [9], Azadirachta indica [7], Lemongrass [10], Aloe vera [11], Cinnamomum Camphora [12], Emblica officinalis 


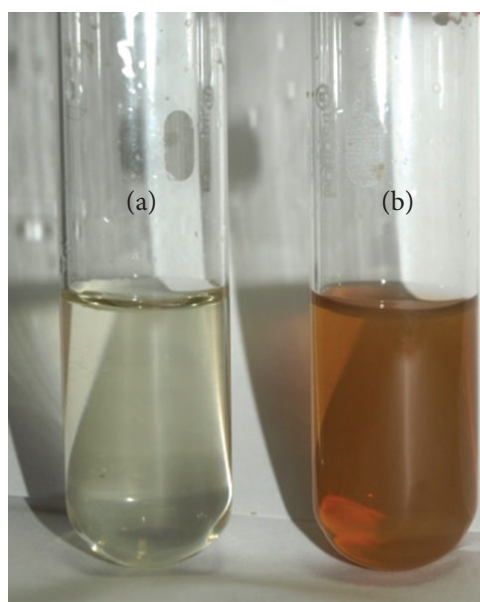

Figure 1: Colour change in reaction mixture (silver nitrate + Tulsi leaves extract) (a) at 0 hours; (b) after 2 hours.

[13], Capsicum annuum [14], Diospyros kaki [15], Carica papaya [16], Coriandrum sp. [17], Boswellia ovalifoliolata [18], Tridax procumbens, Jatropha curcas, Solanum melongena, Datura metel, Citrus aurantium [19], and many weeds $[1,20]$ have shown the potential of reducing silver nitrate to give formation of AgNPs.

Ocimum sanctum (Tulsi) is a medicinal herb abundantly found and cultured in India, Malaysia, Australia, West Africa, and some of the Arab countries [21]. Tulsi leaves have been traditionally used for treatment of many infections. The antibacterial activity has been reported to be the upshot of essential oil components, mostly eugenols found in it. The present study aims at the synthesis of silver nanoparticles from the aqueous extract of Tulsi leaves. We also attempt to combine the inherent antimicrobial activities of silver metal and Tulsi extract for enhanced antimicrobial activity.

\section{Experimental}

2.1. Chemicals. Silver nitrate was purchased from SigmaAldrich, Bangalore, India. The bacteriological media were purchased from HiMedia Laboratories, India. All media and solutions were prepared in double-distilled Milli Q water. The experiments were performed in triplicates, and mean values are presented in results.

2.2. Microorganisms and Media. Common human pathogenic bacterial strains of Escherichia coli ATCC 25922 and Staphylococcus aureus ATCC 25923 were used for assessment of antibacterial activity of lab-synthesized AgNPs. The strains were obtained from National Collection of Industrial Microorganisms (NCIM), Pune (India). They were clinical isolates and are used as international reference standards for disc susceptibility assessment of many antibiotics. Nutrient agar was used for growth and maintenance of bacterial strains. Nutrient broth was used for preparation of suspension cultures. Mueller Hinton Agar (MHA) was used to assess antibacterial activities.

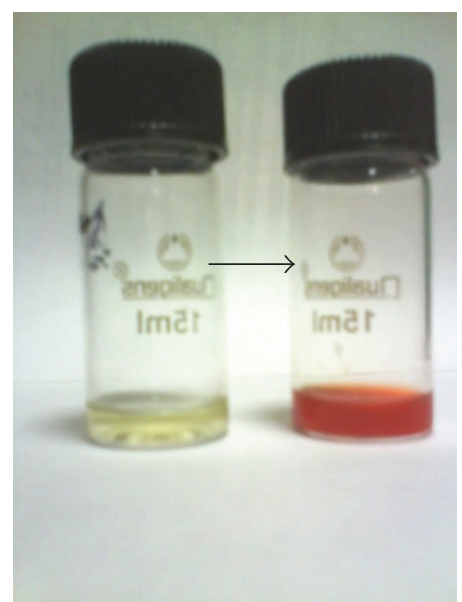

FIgURE 2: Reductase assay for qualitative evaluation of reducing entities in Tulsi extract (colour change from yellow to brick red acts as an indicator of strong reducing potential of Tulsi extract).

2.3. Preparation of Plant Extract. $20 \mathrm{gm}$ of fresh leaves of Tulsi were washed thoroughly with double-distilled water and were then cut into small pieces. These finely cut pieces were then mixed with $100 \mathrm{~mL}$ doubled-distilled water, and this mixture was kept for boiling for a period of 5 minutes. After cooling, it was filtered through Whatman Filter paper no. 1 .

\subsection{Synthesis of AgNPs and Evaluation of Reducing Potential} of the Extract. $10 \mathrm{~mL}$ of aqueous extract of Tulsi leaves was added to $90 \mathrm{~mL}$ of silver nitrate solution so as to make its final concentration to $10^{-3} \mathrm{M}$. The solution was allowed to react at room temperature. Periodic sampling after 30 minutes was carried out to monitor the formation of AgNPs. The qualitative evaluation of reducing potential of aqueous extract of Tulsi leaves was carried out as per the method reported by Saifuddin et al. [22].

\subsection{Analysis of Bioreduced Silver Nanoparticles}

2.5.1. UV-Vis Spectroscopy. UV-Vis spectroscopic analysis was carried out on Shimadzu UV 1800. Cuvette of path length $10 \mathrm{~mm}$ was used. The measurements were carried out as a function of reaction time at room temperature.

2.5.2. Transmission Electron Microscopy. The TEM images of synthesized AgNPs were obtained for size and shape determination using JEOL 200 TEM operated at an accelerating voltage of $300 \mathrm{kV}$. Prior to analysis, AgNPs were sonicated for 5 minutes, and a drop of appropriately diluted sample was placed onto carbon-coated copper grid. The liquid fraction was allowed to evaporate at room temperature.

2.5.3. X-Ray Diffractometry. XRD measurements were recorded on Rigaku Miniflex II X-ray diffractometer. For XRD measurements, the AgNPs were dried in oven at $60^{\circ} \mathrm{C}$, and such dried powder was further analyzed on XRD for 


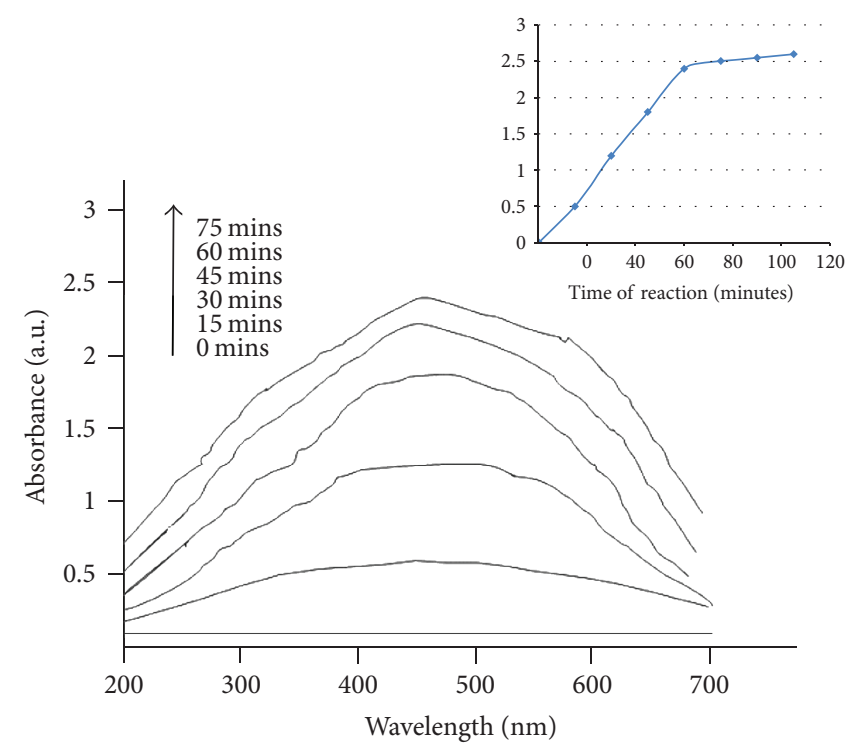

FIGURE 3: UV-Vis absorption spectrum of AgNPs recorded after regular intervals. Inset shows the plot of absorbance at $\lambda_{\max }$ versus reaction time.

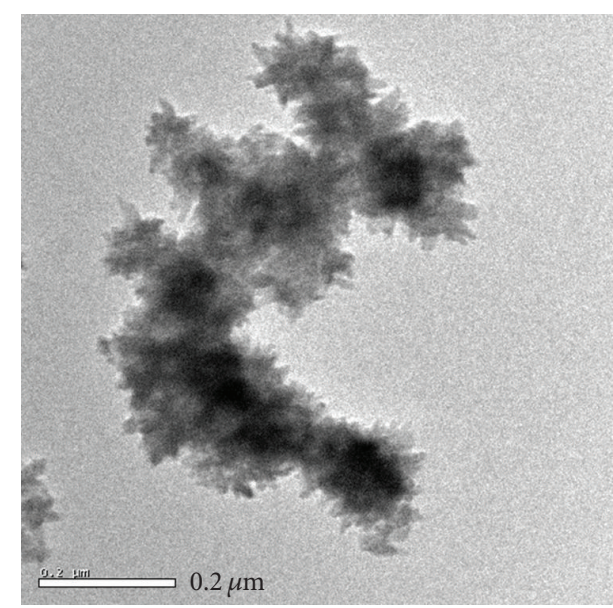

(a)

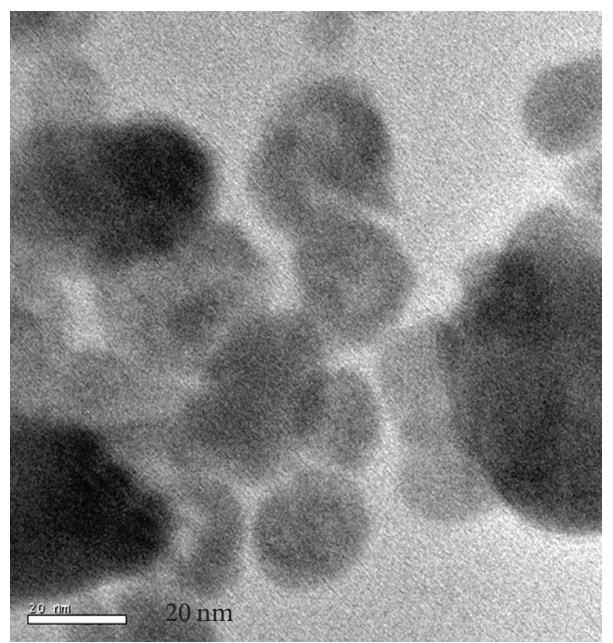

(c)

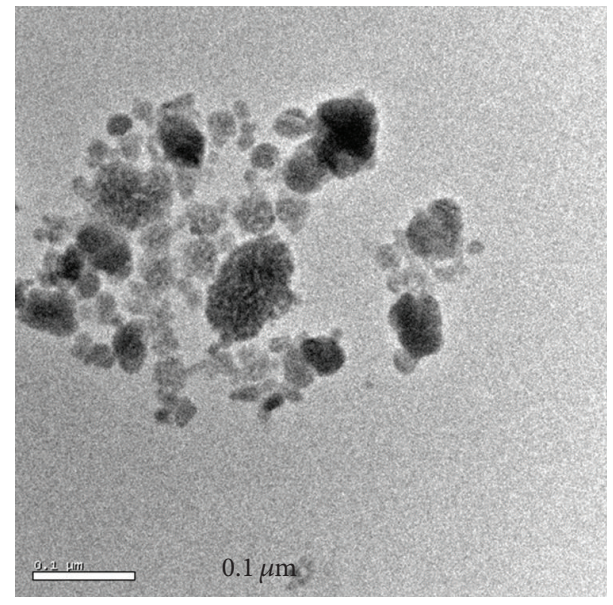

(b)

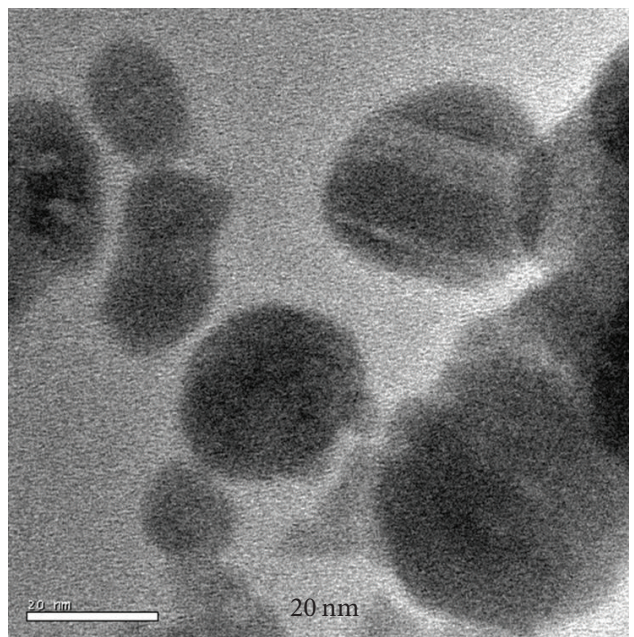

(d)

Figure 4: TEM images of AgNPs at different magnification levels. 


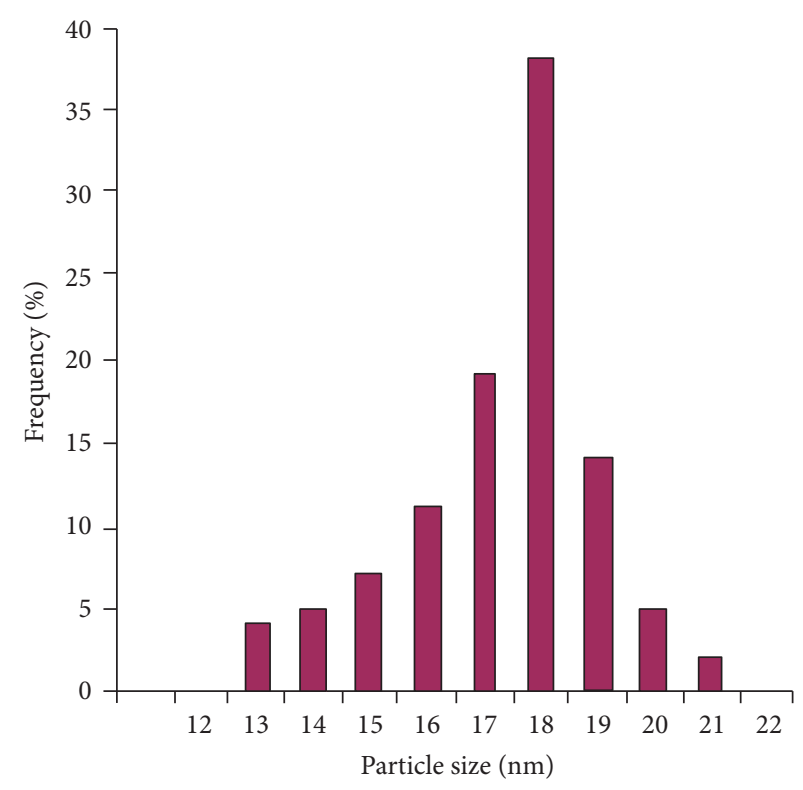

(a)

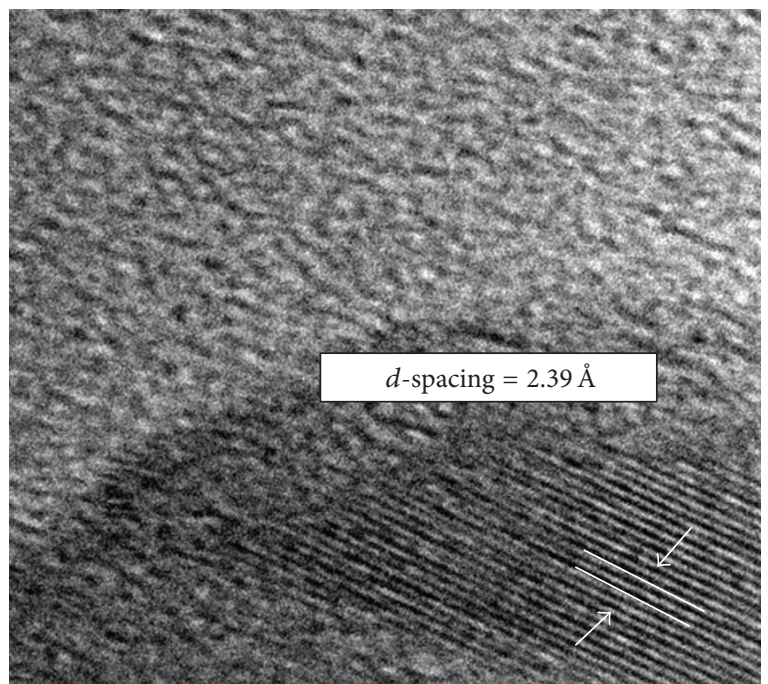

(b)

FIgURE 5: (a) Frequency distribution histogram for particle size of AgNPs; (b) HRTEM images of AgNPs displaying $d$-spacing.

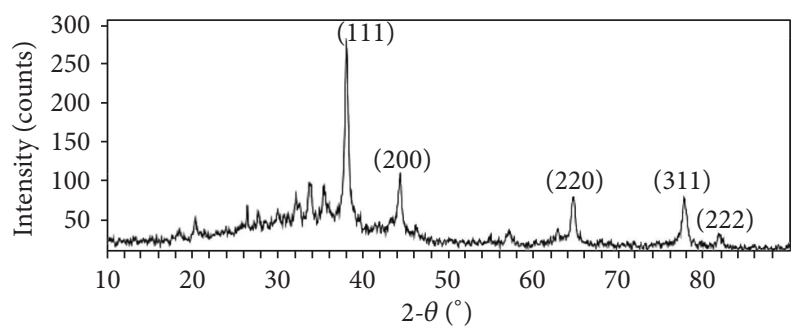

FIGURE 6: XRD pattern of AgNPs.

their phase structure and exact material identification. The $\mathrm{Cu} \alpha$ radiation $(k=1.5418 \AA$ ) was selected and the diffractogram was obtained in the $2 \theta$ range of $10-60$ degree.

2.5.4. Fourier Transform Infrared (FTIR) Spectroscopy. The binding properties of AgNPs synthesized by Tulsi leaf extract were investigated by FTIR analysis. FTIR measurements were taken on Bruker vertex 70. Dried and powdered AgNPs were palleted with potassium bromide (KBr) (1:10 proportion). The spectra were recorded in the wavenumber range of $450-2500 \mathrm{~cm}^{-1}$ and analyzed by subtracting the spectrum of pure $\mathrm{KBr}$.

2.6. Assessment of Antibacterial Activity. In order to examine the antibacterial activity of the AgNPs on selected bacteria, the Kirby-Bauer disc diffusion method [23] was used. For disc diffusion method, log phase bacterial inoculums $\left(10^{8} \mathrm{cfu} / \mathrm{mL}\right)$ were standardized against MacFarland's standard [24] and were swabbed onto petriplates containing $4 \mathrm{~mm}$ thick MHA. Filter paper discs saturated with AgNPs, Tulsi extract and silver nitrate solution were placed onto these

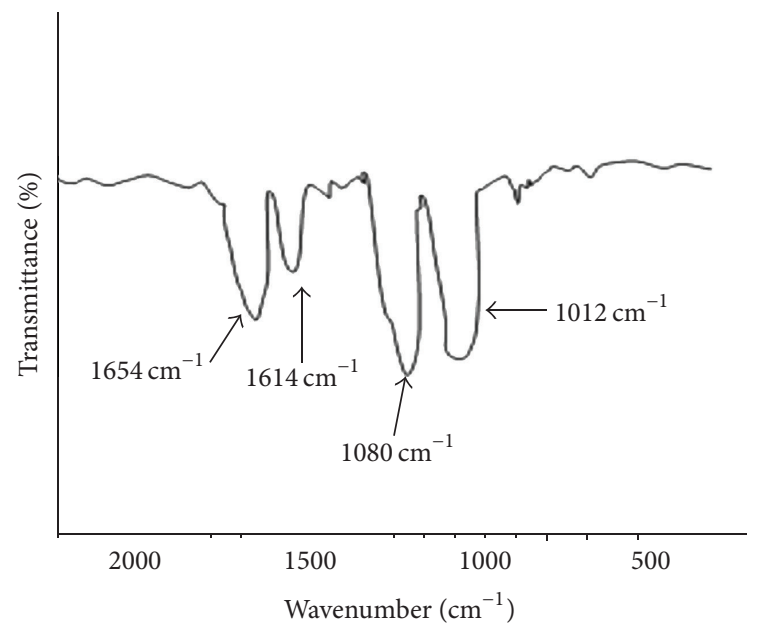

FIgURE 7: FTIR spectrum of AgNPs synthesized by Tulsi extract.

plates with the help of sterile forceps and incubated at $37^{\circ} \mathrm{C}$. A disc soaked in sterile distilled water acted as controls for the experiment. Negative growth zone results were read only after 24 hours, as longer or shorter incubation periods may give misleading results.

\section{Results and Discussion}

Formation of AgNPs by reduction of silver nitrate during exposure to Tulsi leaf extract can be easily monitored from the change in colour of the reaction mixture. Silver nanoparticles bear a characteristic yellow brown colour due to the excitation of surface plasmon vibrations. The change 


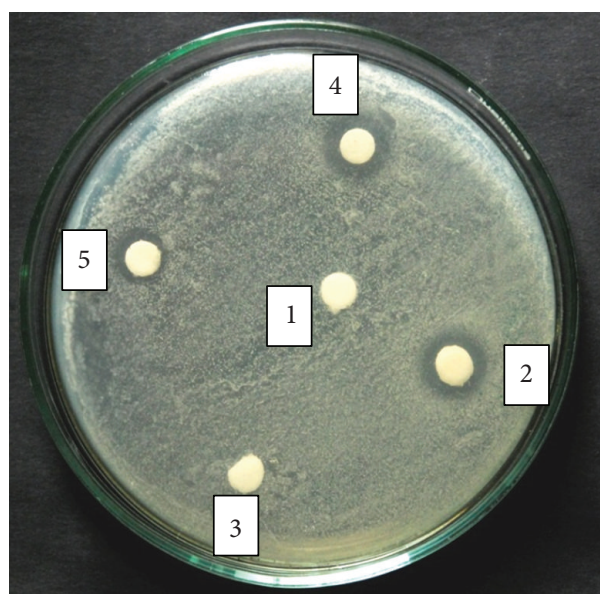

(a)

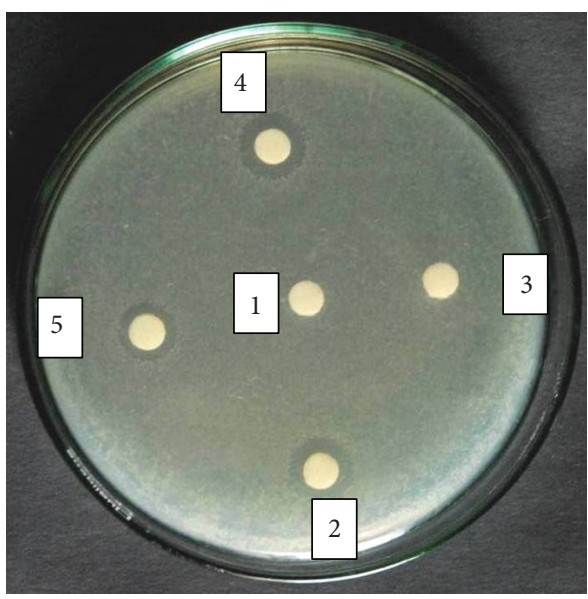

(b)

Figure 8: Plates showing diameters of zones of inhibition of Staphylococcus aureus and E. coli. against distilled water as control (1); Tulsi extract (2); silver nitrate solution (3); AgNPs synthesized by Tulsi extract (4) and water diluted Tulsi extract (dilution factor $1: 1$ ) (5).

in colour of the reaction mixture after 2 hours is presented in Figure 1 which indicated the formation of AgNPs. This formation indicates that silver ions in reaction medium have been converted to elemental silver having the size of nanometric range. There is always an essential need for reducing entities in the reaction medium to bring such conversions. To ensure the presence of reducing entities in the reaction medium, reducing assay was carried out, and the results are shown in Figure 2. It shows the change in colour of the reaction medium as an effect of presence of any type of reducing substance. As per this qualitative assessment of reducing potential of Tulsi extract, presence of significant amount of reducing entities was attested therein. In case of bacteria and fungi mediated synthesis of AgNPs, reduction of silver nitrate to elemental silver has been attributed to the presence of reductive enzymes [22, 25]. But there is controversy regarding the plant extract components involved in reduction of silver nitrate to elemental silver. Shankar et al., (2005) have speculated the role of reducing sugars for the reduction of silver nitrate to silver nanoparticles [10]. In another recent study, it has been suggested that different compounds such as caffeine and theophylline bring out the reduction processes and thus silver nanoparticles synthesis [26]. Natural antioxidants have been reported to have strong reducing ability [27]. As Tulsi possess a potent antioxidant activity [21], we attribute the reduction process to their presence of high quantity of antioxidants in the leaves extract

Figure 3 shows UV-Vis absorption spectrum of silver nanoparticles. Though the plasmon band is broad due to the presence of components in Tulsi extract which are also being read in the spectrophotometric range, it is observed that the silver surface plasmon resonance (SPR) occurs at $450 \mathrm{~nm}$ and steadily increases in intensity as a function reaction time. There is no change in peak position, suggesting that nucleation of silver nanoparticles starts with initiation of reaction time only, and the size remains unchanged throughout the course of reaction. According to Mie theory, only a single SPR band is expected in the absorption spectra of spherical nanoparticles whereas, the number of peaks increases as anisotropy increases [28]. In the present study, SPR band reveals spherical shape of silver nanoparticles, which was further confirmed by TEM. Inset of Figure 3 represents the plot of absorbance at $\lambda_{\max }$ versus reaction time. The reduction of silver ions was quite rapid. More than $90 \%$ of the reaction is complete within 60 minutes of the reaction time. Generally, biosynthetic methods are considered as time consuming when compared with chemical methods. To the best of our knowledge, reaction time of at least 12 hours is required in plant-mediated nanomaterials synthesis. However, the time consumed in the present study for the reaction to complete is severalfold lesser than reported. Such alacrity in reaction time can be the outcome of potent antioxidant activity of the Tulsi extract, which makes the reaction much more efficient than others.

The efficiency of this method was tested for stability also. The solution of AgNPs was stored for two months, and no precipitation in the content of the solution was observed. This was also assured by regular observation of UV-Vis absorption properties of the solution. There was no shift in the absorbance intensity as well as absorption maxima indicating the particle size to be same as recorded earlier.

Figure 4 shows TEM images of AgNPs at different magnifications. Images reveal that the AgNPs are predominantly spherical in shape and are not in physical contact with each other. Lower magnification image reveals the nanoparticles are embedded in a dense matrix which may be the organic stabilizing components of Tulsi leaf extract. The presence of organic content associated with AgNPs can be further confirmed by observing the sharp Braggs reflection in XRD spectrum. Figure 5(a) shows the histogram of particles size versus number of particles observed on TEM grid. It is clear from the histogram that the mean particle size of AgNPs is $18 \mathrm{~nm}$. The HRTEM image of synthesized AgNPs is shown in Figure 5(b). It reveals that the particles exhibit the dspacing of $2.39 \AA$ which correspond to the (111) plane of silver. 
Figure 6 shows the XRD patterns obtained for silver nanoparticles synthesized by Tulsi extract. All major peaks can be indexed for the face centered cubic structure of silver. Minor but broad peaks at lower $2 \theta$ theta values can be assigned to the organic content of the Tulsi extract. The XRD pattern thus clearly shows that silver nanoparticles formed by Tulsi extract are crystalline in nature. The average diameter of the silver particles was calculated from the (111) diffraction peak using Scherrer's formula:

$$
t=\frac{0.9 \lambda}{(\beta \cos \theta)},
$$

where $t$ is mean crystallite size, $\beta$ is the width of the peak at half maximum intensity of a specific phase in radians, and $\lambda$ is the wavelength of incident rays, $\theta$ is the center angle of the peak in radian.

The mean crystallite size for AgNPs synthesized using Tulsi extract was determined to be $16.87 \mathrm{~nm}$ by formula which is comparable with the results obtained by HRTEM analysis.

Figure 7 shows the FTIR analysis results of the AgNPs. The prominent peaks were observed at 1012, 1080, 1614, $1654 \mathrm{~cm}^{-1}$. There appeared no peaks in the wavenumber range $3400-3250 \mathrm{~cm}^{-1}$, that is, amide region (region omitted from the spectrum). This is contradictory to earlier literature reports stating that binding as well as stabilization takes place by free amide groups present in proteinaceous substance used for synthesis $[28,29]$. In the present study, the peaks are more characteristic of eugenols, linalools, and terpenes that are abundant in Tulsi plant extract. The peaks found at 1614 and $1654 \mathrm{~cm}^{-1}$ can be attributed to the C-C in alkene rings and $\mathrm{C}=\mathrm{C}$ stretch of aromatic rings, respectively, whereas peaks at 1012 and $1080 \mathrm{~cm}^{-1}$ can be attributed to the ether linkages. Depending on above observation, it can be assumed that the stabilization is achieved by the phenolic as well as aromatic compounds present in the extract.

Antibacterial potential of silver is known for many years [28]. Tulsi extract has also been much exploited, both traditionally and commercially, for their antibacterial potential which is an upshot of essential oil components [30]. In our study, the AgNPs synthesized using Tulsi extract exerted a fairly significant antibacterial action on the tested bacteria. This is evident by the values of diameter of zone of inhibition obtained during assessment of antibacterial activity (Table 1). Figure 8 shows the zones of inhibition of E. coli and Staphylococcus aureus against AgNPs, silver nitrate, Tulsi extract and distilled water as control. For both the bacterial strains, no zone of inhibition was observed for control as well as silver nitrate solution. A very small but noticeable zone of inhibition was observed for Tulsi extract. This symbolizes that the antimicrobial potential of Tulsi extract is higher than that of silver ions at their respective concentrations used in the study. Bioreduced silver nanoparticles showed considerable growth inhibition of two of the well-known pathogenic bacterial species. Zones of $11 \mathrm{~mm}$ and $10 \mathrm{~mm}$ were observed for E. coli and Staphylococcus aureus, respectively. Coupling of inherent property of Tulsi extract with that of silver nanoparticles has really proved to be beneficial to minimize
TABLE 1: Values of zones of inhibition obtained by disc diffusion method.

\begin{tabular}{lcc}
\hline \multirow{2}{*}{ Components } & \multicolumn{2}{c}{ Diameter of zone of inhibition in mm } \\
& E. coli & Staphylococcus aureus \\
\hline Distilled water (control) & $\mathrm{NZ}$ & $\mathrm{NZ}$ \\
Silver nitrate solution & $\mathrm{NZ}$ & $\mathrm{NZ}$ \\
Tulsi extract & 08 & 08 \\
AgNPs & 11 & 10 \\
\hline
\end{tabular}

(NZ: no zone of inhibition).

the dose that needs to be administered for total microbial reduction.

\section{Conclusion}

Highly monodisperse AgNPs silver nanoparticles are synthesized using leaf extract of a well-known medicinal herb, Tulsi. The synthesis is found to be efficient in terms of reaction time as well as stability of the synthesized AgNPs. This nanoparticulate solution exhibits excellent stability for six months from the date of synthesis. The process is truly scalable owing to lesser specificity of reaction parameters. Investigation on the antibacterial activity of AgNPs against $E$. coli and Staphylococcus aureus reveals high potential of Tulsi extract stabilized AgNPs to be used as antimicrobial agent in medical field as well as food and cosmetic industries.

\section{References}

[1] N. Roy and A. Barik, "Green synthesis of silver nanoparticles from the unexploited weed resources," International Journal of Nanotechnology, vol. 4, p. 95, 2010.

[2] A. Leela and M. Vivekanandan, "Tapping the unexploited plant resources for the synthesis of silver nanoparticles," African Journal of Biotechnology, vol. 7, no. 17, pp. 3162-3165, 2008.

[3] M. Kowshik, N. Deshmukh, W. Vogel, J. Urban, S. K. Kulkarni, and K. M. Paknikar, "Microbial synthesis of semiconductor CdS nanoparticles, their characterization, and their use in the fabrication of an ideal diode," Biotechnology and Bioengineering, vol. 78, no. 5, pp. 583-588, 2002.

[4] T. Klaus-Joerger, R. Joerger, E. Olsson, and C. G. Granqvist, "Bacteria as workers in the living factory: metal-accumulating bacteria and their potential for materials science," Trends in Biotechnology, vol. 19, no. 1, pp. 15-20, 2001.

[5] K. Govindaraju, S. Tamilselvan, V. Kiruthiga, and G. Singaravelu, "Biogenic silver nanoparticles by Solanum torvum and their promising antimicrobial activity," Journal of Biopesticides, vol. 3, no. 1, pp. 394-399, 2010.

[6] D. Mandal, M. E. Bolander, D. Mukhopadhyay, G. Sarkar, and P. Mukherjee, "The use of microorganisms for the formation of metal nanoparticles and their application," Applied Microbiology and Biotechnology, vol. 69, no. 5, pp. 485-492, 2006.

[7] S. S. Shankar, A. Rai, A. Ahmad, and M. Sastry, "Rapid synthesis of $\mathrm{Au}, \mathrm{Ag}$, and bimetallic Au core-Ag shell nanoparticles using Neem (Azadirachta indica) leaf broth," Journal of Colloid and Interface Science, vol. 275, no. 2, pp. 496-502, 2004. 
[8] S. S. Shankar, A. Ahmad, and M. Sastry, "Geranium leaf assisted biosynthesis of silver nanoparticles," Biotechnology Progress, vol. 19, no. 6, pp. 1627-1631, 2003.

[9] J. L. Gardea-Torresdey, E. Gomez, J. R. Peralta-Videa, J. G. Parsons, H. Troiani, and M. Jose-Yacaman, "Alfalfa sprouts: a natural source for the synthesis of silver nanoparticles," Langmuir, vol. 19, no. 4, pp. 1357-1361, 2003.

[10] S. S. Shankar, A. Rai, A. Ahmad, and M. Sastry, "Controlling the optical properties of lemongrass extract synthesized gold nanotriangles and potential application in infrared-absorbing optical coatings," Chemistry of Materials, vol. 17, no. 3, pp. 566-572, 2005.

[11] S. P. Chandran, M. Chaudhary, R. Pasricha, A. Ahmad, and M. Sastry, "Synthesis of gold nanotriangles and silver nanoparticles using Aloe vera plant extract," Biotechnology Progress, vol. 22, no. 2, pp. 577-583, 2006.

[12] J. Huang, Q. Li, D. Sun et al., "Biosynthesis of silver and gold nanoparticles by novel sundried Cinnamomum camphora leaf," Nanotechnology, vol. 18, no. 10, Article ID 105104, 2007.

[13] B. Ankamwar, C. Damle, A. Ahmad, and M. Sastry, "Biosynthesis of gold and silver nanoparticles using Emblica officinalis fruit extract, their phase transfer and transmetallation in an organic solution," Journal of Nanoscience and Nanotechnology, vol. 5, no. 10, pp. 1665-1671, 2005.

[14] S. Li, Y. Shen, A. Xie et al., "Green synthesis of silver nanoparticles using Capsicum annuum L. extract," Green Chemistry, vol. 9, no. 8, pp. 852-858, 2007.

[15] J. Y. Song and B. S. Kim, "Biological synthesis of bimetallic $\mathrm{Au} / \mathrm{Ag}$ nanoparticles using Persimmon (Diopyros kaki) leaf extract," Korean Journal of Chemical Engineering, vol. 25, no. 4, pp. 808-811, 2008.

[16] D. Jain, H. Kumar Daima, S. Kachhwaha, and S. L. Kothari, "Synthesis of plant-mediated silver nanoparticles using papaya fruit extract and evaluation of their anti microbial activities," Digest Journal of Nanomaterials and Biostructures, vol. 4, no. 3, pp. 557-563, 2009.

[17] K. B. Narayanan and N. Sakthivel, "Coriander leaf mediated biosynthesis of gold nanoparticles," Materials Letters, vol. 62, no. 30, pp. 4588-4590, 2008.

[18] S. Ankanna, T. N. V. K. V. Prasad, E. K. Elumalai, and N. Savithramma, "Production of biogenic silver nanoparticles using Boswellia ovalifoliolata stem bark," Digest Journal of Nanomaterials and Biostructures, vol. 5, no. 2, pp. 369-372, 2010.

[19] P. Rajasekharreddy, P. U. Rani, and B. Sreedhar, "Qualitative assessment of silver and gold nanoparticle synthesis in various plants: a photobiological approach," Journal of Nanoparticle Research, vol. 12, no. 5, pp. 1711-1721, 2010.

[20] V. Parashar, R. Parashar, B. Sharma, and A. C. Pandey, "Parthenium leaf extract mediated synthesis of silver nanoparticles: a novel approach towards weed utilization," Digest Journal of Nanomaterials and Biostructures, vol. 4, no. 1, pp. 45-50, 2009.

[21] S. Mondal, B. R. Mirdha, and S. C. Mahapatra, "The science behind sacredness of Tulsi (Ocimum sanctum linn.)," Indian Journal of Physiology and Pharmacology, vol. 53, no. 4, pp. 291-306, 2009.

[22] N. Saifuddin, C. W. Wong, and A. A. N. Yasumira, "Rapid biosynthesis of silver nanoparticles using culture supernatant of bacteria with microwave irradiation," E-Journal of Chemistry, vol. 6, no. 1, pp. 61-70, 2009

[23] A. W. Bauer, W. M. Kirby, J. C. Sherris, and M. Turck, "Antibiotic susceptibility testing by a standardized single disk method," American Journal of Clinical Pathology, vol. 45, no. 4, pp. 493-496, 1966.

[24] C. W. Hanson and W. J. Martin, "Modified agar dilution method for rapid antibiotic susceptibility testing of anaerobic bacteria," Antimicrobial Agents and Chemotherapy, vol. 13, no. 3, pp. 383-388, 1978.

[25] A. Ahmad, P. Mukherjee, S. Senapati et al., "Extracellular biosynthesis of silver nanoparticles using the fungus Fusarium oxysporum," Colloids and Surfaces B, vol. 28, no. 4, pp. 313-318, 2003.

[26] C. Krishnaraj, E. G. Jagan, S. Rajasekar, P. Selvakumar, P. T. Kalaichelvan, and N. Mohan, "Synthesis of silver nanoparticles using Acalypha indica leaf extracts and its antibacterial activity against water borne pathogens," Colloids and Surfaces B, vol. 76, no. 1, pp. 50-56, 2010.

[27] Y. Zhou, W. Lin, J. Huang et al., "Biosynthesis of gold nanoparticles by foliar broths: roles of biocompounds and other attributes of the extracts," Nanoscale Research Letters, vol. 5, no. 8, pp. 1351-1359, 2010.

[28] W. Raut Rajesh, R. Lakkakula Jaya, S. Kolekar Niranjan, D. Mendhulkar Vijay, and B. Kashid Sahebrao, "Phytosynthesis of silver nanoparticle using Gliricidia sepium (Jacq.)," Current Nanoscience, vol. 5, no. 1, pp. 117-122, 2009.

[29] P. Mukherjee, M. Roy, B. P. Mandal et al., "Green synthesis of highly stabilized nanocrystalline silver particles by a nonpathogenic and agriculturally important fungus T. asperellum," Nanotechnology, vol. 19, no. 7, Article ID 075103, 2008.

[30] P. Prakash and N. Gupta, "Therapeutic uses of Ocimum sanctum Linn (Tulsi) with a note on eugenol and its pharmacological actions: a short review," Indian Journal of Physiology and Pharmacology, vol. 49, no. 2, pp. 125-131, 2005. 

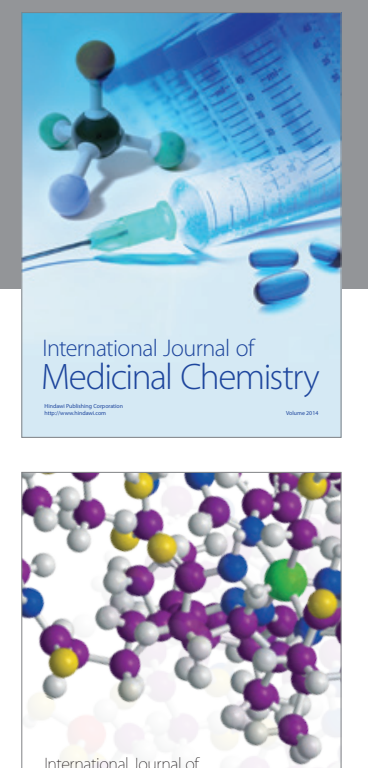

\section{Carbohydrate} Chemistry

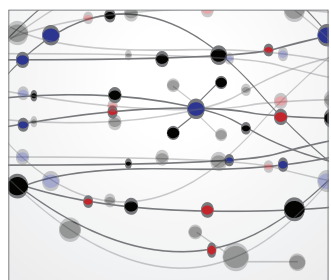

The Scientific World Journal
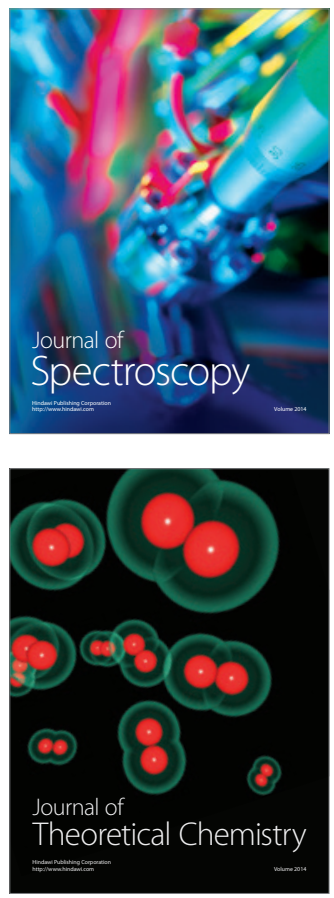
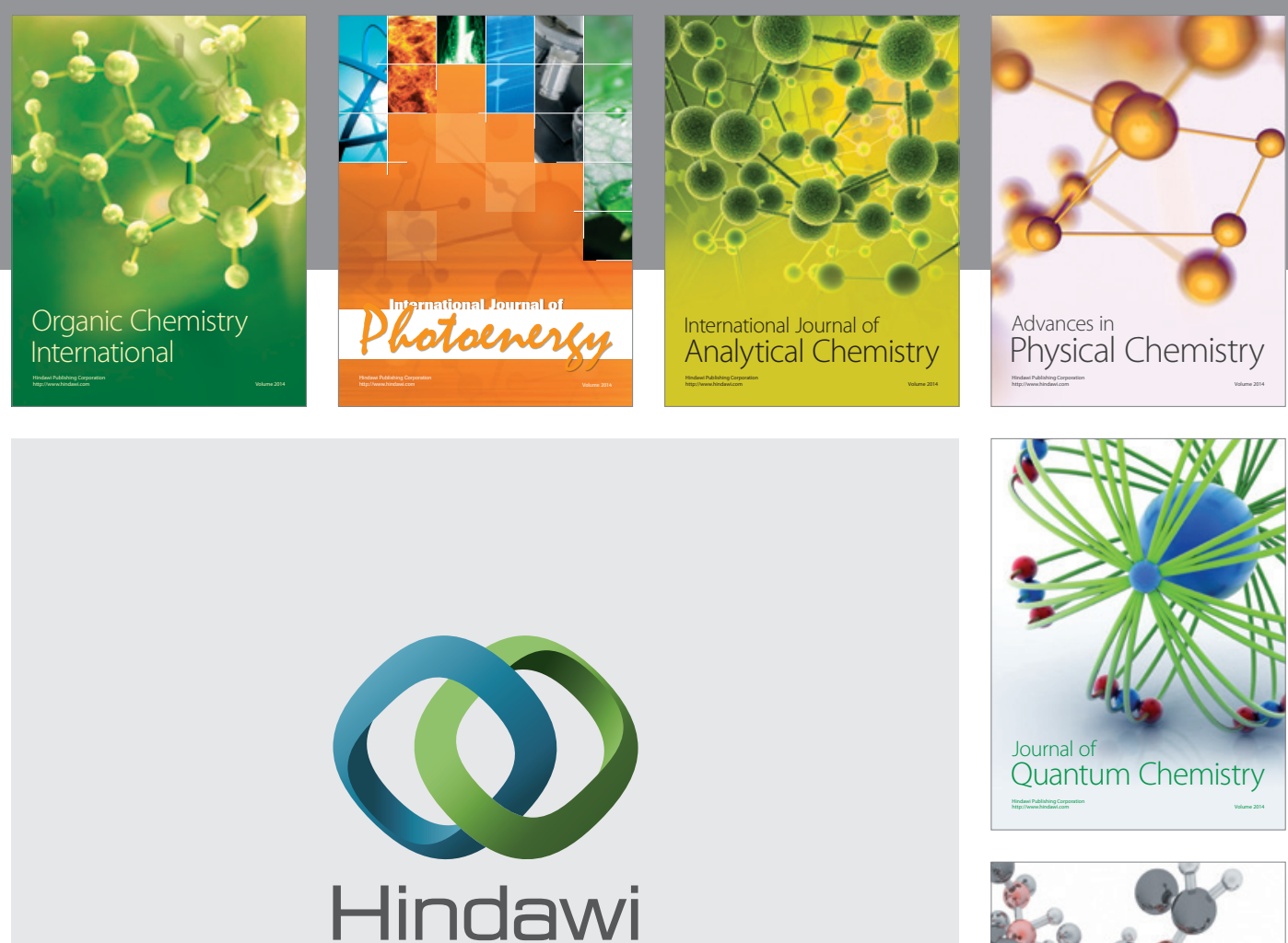

Submit your manuscripts at

http://www.hindawi.com

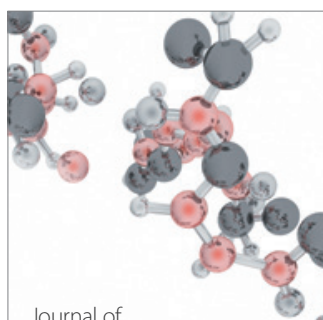

Analytical Methods

in Chemistry

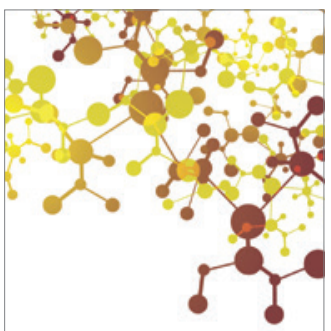

Journal of

Applied Chemistry

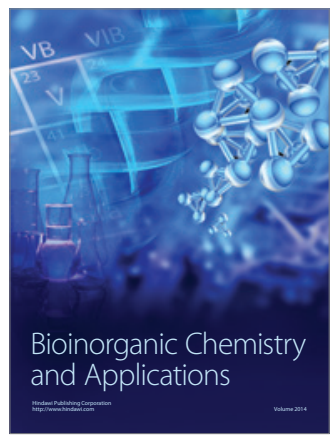

Inorganic Chemistry
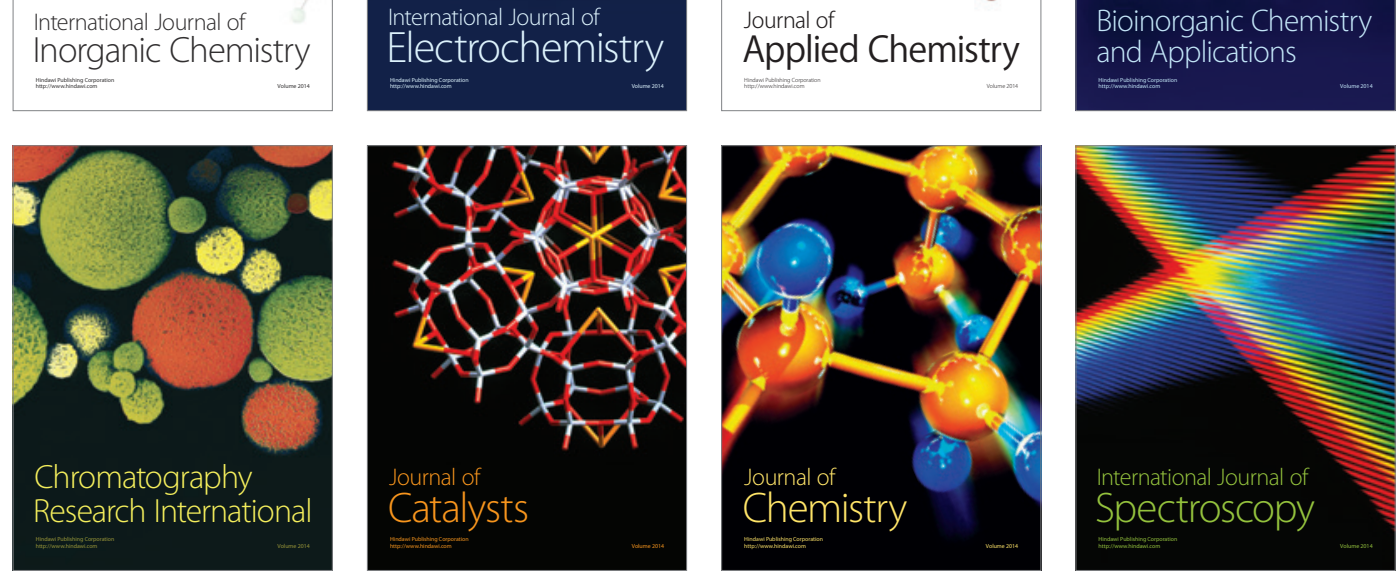